\title{
Latent classes of substance use in adolescent cannabis users: predictors and subsequent substance-related harm
}

\author{
Jean-Sébastien Fallu ${ }^{1,2}$ *, Frédéric N. Brière ${ }^{3}$ and Michel Janosz ${ }^{1,2,3}$ \\ 1 École de Psychoéducation, Université de Montréal, Montréal, QC, Canada \\ 2 Institut de Recherche en Santé Publique de I'Université de Montréal, Montréal, QC, Canada \\ ${ }^{3}$ School Environment Research Group, Université de Montréal, Montréal, OC, Canada
}

\section{Edited by:}

Elizabeth Clare Temple, University of

Ballarat, Australia

\section{Reviewed by:}

Aviv M. Weinstein, University of Bristol, UK

Antoni Gual, Hospital Clínic de

Barcelona, Spain

\section{*Correspondence}

Jean-Sébastien Fallu, École de Psychoeducation, Université de Montréal, C.P. 6128, Succursale Centre-Ville, Montréal, QC H3C 3J7, Canada

e-mail: jean-sebastien.fallu@ umontreal.ca
Cannabis use is highly prevalent in late adolescence, but not all users experience significant negative consequences. Little information is available to identify the substance use patterns and risk factors of users who are at greater risk of experiencing negative consequences. In this prospective study, we aimed to empirically identify latent classes of substance use in adolescent cannabis users and to examine how these classes relate to antecedent psychosocial predictors and subsequent substance-related outcomes. The sample was recruited from 68 high schools in Quebec and consisted of 1618 participants who reported using cannabis in grade 10 . We used latent class analysis to empirically identify classes of users based on the age of onset, frequency, and typical quantity of cannabis and other substance use, as well as substance mixing behaviors. We then compared classes in terms of (a) sociodemographic and psychosocial predictors in grades 7-8 and (b) substance-related consequences in grade 11. Four distinct classes were identified: Late-Light Users (28\%); Late-Heavy + Polydrug Users (14\%); Early-Moderate Users (33\%); Early-Heavy + Polydrug Users (26\%). Late-Light Users reported the lowest levels of substance use, while Early-Heavy + Polydrug Users reported the highest levels. Intermediate levels of substance use were found in the other two classes. Sex, age, delinquency, peer delinquency, school bonding, parental monitoring, and parental conflict all helped to differentiate classes. Class membership predicted substance-related harm, with greater consequences in early- and late-onset heavy using classes. In light of results, in addition to age and sex, screening and intervention for risky cannabis use among adolescents should focus on school bonding in order to target the most risky late-onset adolescents and on peer delinquency in order to target the most risky early-onset ones.

Keywords: cannabis use, substance use, classes, adolescents, substance-related problems

\section{INTRODUCTION}

Cannabis is the illicit drug most widely used in adolescence. By late adolescence, cannabis use is a relatively normative behavior. The latest available figures of annual cannabis use by late adolescents in North-America vary from close to $40 \%$ in the USA (1) to close to $50 \%$ in Quebec, Canada (2). More than $80 \%$ of 12 graders find it easy or very easy to have access to cannabis (1). Fortunately, not all cannabis users experience significant negative consequences $(3,4)$, but some do. A key task of prevention science is to better understand the classes of use, the characteristics of users, and other factors that are related to problematic use. The idea that some use classes are more at risk than others is often put forward $(5,6)$, but rarely put to the test. A few studies have described typologies of cannabis users, but most have studied clinical samples or have focused mostly on specific problems or solely on cannabis use indicators (6-8). Little information is currently available in the literature to allow identifying and distinguishing between subgroups of cannabis users at higher and lower risk of impairments, which would be critical to improving screening and prevention.

Examining natural heterogeneity in classes of cannabis use may be one helpful strategy to understand why some users experience more problematic consequences than others. Many studies have documented the acute and/or chronic health risks or harms associated with cannabis use. These include cannabis dependence, fatal and non-fatal motor-vehicle accidents under the influence of cannabis, cognitive impairments, respiratory impairments, and the amplification or onset of psychosis, especially in predisposed individuals (9-16). Specifically, studies suggest that several key cannabis use characteristics are most predictive of such harm outcomes. These include frequent (e.g., weekly or more often) or chronic cannabis use, and early-onset of cannabis use (11,17-20). Because many adolescent cannabis users are polydrug users $(2,21)$, classes of use also have to take multiple substances into account, including alcohol. Indeed, most cannabis users take it simultaneously with alcohol (22-24), which could be a particular risk for youngsters (25). To our knowledge, no study compared the consequences of empirically derived cannabis use classes in a normative population of adolescents.

Studying psychosocial predictors of heterogeneity in cannabis use classes is also important. This allows identifying factors, which anticipate high-risk substance use patterns vs. low-risk substance use patterns. Many categories of predictors can be useful to predict 
heterogeneity in patterns. For instance, a recent study by Chabrol et al. (7) applied a cluster analysis to a sample of adolescents cannabis users on the basis of personality traits and found three groups: "ordinary," below the mean on several measures of personality, "borderline," with high levels of borderline traits, depressed moods, and social anxiety, and a least prevalent cluster called "impulsive," which was well above the mean on impulsivity and callous traits but low on other measures. As expected, the frequency of use was higher in the latter two clusters.

In addition to those considered by Chabrol et al. (7), other factors from other domains of influence might be useful and important in predicting heterogeneity. Babor et al. (26) suggested that classification schemes must be multidimensional in order to be useful in predicting outcomes. Accordingly, in order to achieve such classification, one must rely on diverse individual and relational risk factors for substance abuse, use-related problems, as well as substance use patterns. Severity of substance use (27), the level of comorbid psychopathology $(28,29)$, or delinquency $(30)$ have been common dimensions of classification for adolescent substance abusers, but very few studies have relied on multiple dimensions of risk, use, and related problems. A strong predictor of adolescent substance abuse, family conflict (31), that has been useful in distinguishing "Aggressive/Versatile" delinquents, the most severe and chronic subtype (32), and deviant peer affiliation, which is also a robust predictor of adolescent substance abuse (33) was rarely considered in classification efforts. In sum, relevant factors may include familial conflict and monitoring, peer substance use, school bonding and achievement as well as sex, in addition to the one considered by Chabrol et al. (7), which all proved to be useful in predicting use indicators $(31,34,35)$.

Until now, past studies have proposed several typologies based on theoretical grounds and those who used an empirical approach have only shed light on some aspects of reality. Many of these studies focused on alcohol use only (36-38), but some have proposed specific typologies of cannabis users. For instance, among adults, Thomas et al. (39) used epidemiological data to derive a cannabis use typology based on use frequency as well as related harm. Their typology included abstinent and past users. Among users, they proposed three groups: low-risk (26\%), moderate-risk (72\%), and high-risk/dependent (2\%). In terms of empirical studies, Fischer et al. (5) derived a typology of cannabis users, but this study was realized among adults, with a cross-sectional design and focused only on cannabis use indicators (e.g., onset, actual use, daily use, quantity, with whom, medical reasons) to derive their four-group typology: occasional/light use $(31.8 \%)$, moderate-monthly use $(20.2 \%)$, moderate-weekly use (25.2\%), and near-daily or daily use (22.9\%). Reboussin et al. (8) aimed to describe patterns of marijuana involvement during the middle-school years in a sample of African-American adolescents. They also included non-users and used latent class analysis (LCA) on the same cannabis use indicators measured over 3 years. Three classes were identified: little or no involvement $(85,71,55 \%$ in sixth, seventh, and eighth grade, respectively), marijuana exposure opportunity (12, 19, and 26\%), and marijuana use and problems (2, 9, and 19\%). Another study looked at the typology of cannabis-related harm instead of use indicators in a community sample of 14-24 years old throughout 10 years (6). Four substance categories were considered: alcohol, nicotine, cannabis, and illegal drugs other than cannabis. Four groups were identified: Non-problematic (59.2\%); primary alcohol use disorders (14.4\%); delinquent cannabis/alcohol DSM-IVabuse (17.9\%); and CUD with multiple problems (8.5\%). Another cross-sectional study used cluster analysis on a clinical sample of mostly juvenile justice involved adolescents who sought drug abuse treatment (40). They identified three groups based on individual and family risk factors, associated problems, and severity of substance use: Juvenile Justice Involved Substance Abusers (41\%, lowest level of risk but highest juvenile justice involvement); Comorbid Substance Abusers (33\%, greatest family risk and individual psychopathology); and Heavy Substance Abusers (26\%, serious substance abuse and peer substance use). Variables included were substance use, psychiatric disorders, and legal involvement; peer substance use; family substance abuse; parental psychopathology; and family conflict. This multidimensional typology support the idea that risk factors, associated problems, and substance use severity are all critical in explaining heterogeneity.

Several limitations characterize previous studies. First, the variety of designs used in these studies complicates comparisons between them. Second, few studies have examined subgroups of cannabis users (or heterogeneity in cannabis use) and many of the classification efforts were limited to clinical samples (40). Finally, cannabis use severity and important risk factors, such as peer deviancy, parental monitoring, and school bonding, have typically been omitted in previous typologies.

In this study, we aim to empirically identify subgroups of adolescent cannabis users and examine how these subgroups differ in terms of early risk factors and subsequent consequences. We extend prior work by focusing on a general population of adolescent and by using a comprehensive prospective design. We use latent class analysis (41), which allows assigning individuals to relatively homogeneous classes on a probabilistic basis. An increasing number of recent studies have applied LCA to identify subgroups of substance users $(5,6,42-46)$. A main methodological benefit of the LCA approach is that it groups users according to a multiplicity of observed characteristics (e.g., substance use behaviors), as opposed to examining such characteristics separately. This approach is thus a powerful tool to identify and compare multidimensional classes of cannabis users and their associated characteristics.

\section{MATERIALS AND METHODS PARTICIPANTS}

The sample was recruited from 68 high schools in Quebec within the context of the evaluation of the new approaches new solutions (NANS) dropout prevention program (2002-2008) (47). Participants attended secondary schools in disadvantaged communities of the province of Quebec (Canada). NANS schools were selected using stratified random sampling to be representative of all schools in disadvantaged areas of Quebec in terms of geographical location, size, and language (47). Data were obtained via self-reported questionnaires administered in class by teachers supervised by trained and supervised experimenters. Seventy-seven percent of eligible participants provided free and informed consent to participate in the study. All procedures were approved from the Arts and Science Faculty Ethical Review Board at University of Montreal. 
Participants for this study were a cohort assessed annually from grade 7 to grade 11 (2003-2008). The sample for the present study included all participants who provided information on cannabis use in grade $11(N=1618)$. Participants were mostly Quebecborn Caucasians (93\%). Other participants were from a diversity of ethnicities. The sample included slightly more females (53\%) than males $(47 \%)$.

Self-reported substance-use behaviors were collected in grade 10. Predictors were considered in grade 7 and 8 and outcomes in grade 11. Available data for outcomes in grade 11 were $61 \%$ ). Rates of available data for predictors in grades $7-8$ ranged from 80 to $99 \%$.

\section{MEASURES}

\section{Substance use behaviors (grade 10)}

Substance use measures were mostly taken from the ESPAD questionnaire $(48,49)$, a European national substance-use survey of a representative sample of high school students. Its reliability and validity have been verified in the content of many methodological studies [see Ref. (49)]. These measures included past-year alcohol and cannabis use frequency. Original items had seven categories: 1: “0”; 2: “1-2”; 3: “3-5”; 4: “6-9"; 5: “10-19”; 6: “20-39"; and 7: " 40 or more." Some categories of the original items were collapsed together, based on their distributions and on the literature $(1,2)$, in order to limit the number of categories and get clinically significant grouping while avoiding the estimation of a large amount of parameters in the analyses. This resulted in three categories of alcohol and cannabis use frequency: 0 : "0-5"; 1 : “6-30"; and 2: “31 or more." We also used the quantity of alcohol consumed in a typical occasion. Again, some categories were collapsed together for the same reasons. This led to a variable in three categories: 0 : " 0 3"; 1: "4-6"; and 2: "6 or more." We also added a home measure of the quantity of cannabis taken in a typical occasion and collapsed the categories in two: 0 : "1 joint or less"; and 1: "more than a joint." Binge drinking was also measured using the ESPAD item with collapsed categories: 0: "never"; 1 : "1 or 2 times"; and 2: "3 or more times." Other items were taken from a validated measure of adolescent social and personal adjustment (50): stimulant-hallucinogens use ("never"; " 1 or 2 times"; " 3 or more times") as well as two items of alcohol and cannabis use in order to derive alcohol and cannabis use early-onset (grade 8 or earlier). The cannabis and alcohol onset measures are exceptions in the sense that contrarily to other substance use measures, they were derived from grade 7 and 8 items of alcohol and cannabis use frequency. Frequency of tobacco use was measured with a home measure in which categories have been collapsed in the following groups: 0: "never"; 1: less than one per day or "occasional"; and 2: one per day or more or "regular." Finally, the simultaneous use of alcohol and cannabis was also assessed by a house measure and was coded 0: "never"; 1: "1 or 2 times"; and 2 : "3 or more times." We included this measure as this particular behavior has been associated with negative consequences in previous work (22). All items were referring to the past 12 months except for binge drinking and tobacco use (past 30 days).

\section{Substance-related problems (grade 11)}

The outcome measure is largely based on the DEP-ADO scale, widely used to screen substance related problems in Quebec (51,
52). This instrument includes 11 items to which we added 3 to include other important substance-related consequences (fights, unprotected or unwanted sex, intoxication in school) for a total of 14 items $(\alpha=0.88)$. Each item measures the occurrence of different attributed substance-related consequences covering various types of negative consequences, such as legal, school, relational, health, and dependence consequences. Items have been coded 0 (never) and 1 (yes) in accordance with participants' attributions. A confirmatory factorial analysis (53) indicated that all items could be grouped in a single scale (not shown; results can be obtained upon request).

\section{Sociodemographic and psychosocial predictors (grade 7-8)}

Sociodemographic and psychosocial factors used to predict latent classes were selected on the basis of existing theoretical and empirical literature $(31,34,35,54,55)$. Parental monitoring and conflict with parents, delinquent behaviors, peer deviancy, and school bonding and achievement were measured with scales taken from the same questionnaire used for substance use measures, the MASPAQ (50). Parental monitoring was measured with two items asking about parental knowledge of whom their adolescent is with when not at home and where he or she is ("never," "occasionally," "often," "all the time"). Conflict with parents is measured with three items asking about disputes and disagreements with parents with the same item scale. Delinquent behaviors are measured from the presence or absence of a variety of delinquent behaviors (e.g., property crime, fights). Peer delinquency is measured from three items asking about friends' drug use, and if friends had or could have had trouble with the police. These items respectively have the following scales: "never," "now and then," "sometimes," “often," "always"; "none," "one or two," "several," “many”; “strongly disagree," “disagree,” “don't know," “agree,” "strongly agree." School bonding was measured with four items (e.g., I like school; I like what we do in school). The scale is a valence scale with seven categories. Finally, school achievement was measured with two items asking for grades in maths and in French. Depressive symptoms were assessed using the Center for Epidemiologic Studies-Depression (CES-D) scale (56). The CES-D includes 20 items that explore how participants felt or behaved in the past week. The CES-D has been validated for use in French and adolescents $(57,58)$. Internal consistency was adequate with Cronbach's alpha ranging from 0.87 to 0.91 across time points. Sociodemographic factors included sex, age, and family adversity as measured by a cumulative index of nine family risk factors (e.g., low parental occupational prestige, low family wealth, parental separation). All previous factors except age and sex were derived from a mean of scores measured in grade 7 and 8 .

\section{STATISTICAL ANALYSES}

Latent class analysis was used to identify subgroups of cannabis users. This statistical method aims to identifying the most parsimonious classification of individuals into latent classes by maximizing homogeneity within, and heterogeneity between classes. In order to determine the optimal number of classes, different number of latent classes was modeled starting from 1 (e.g., only one class of cannabis users), then 2 , and so on until we reach an optimal 
solution. Different criteria were used to select the most appropriate model (59). These criteria included the following information criteria: deviance, the Akaike information criterion (AIC) (60), the Bayesian information criterion (BIC), and the sample-size adjusted Bayesian information criterion (SSBIC) (61), to compare the relative fit of solutions. Better fitting solutions are reflected in lower values on the indices. We also considered likelihood ratio tests, including the Vuong-Lo-Mendell-Rubin and Lo-MendellRubin adjusted likelihood ratio tests - ALRTs (62). ALRT tests are adequate for non-nested mixture models and test the significance of the difference in fit between two models with a one class difference. We also considered the recommended Bootstrapped Likelihood Ratio Test [BLRT; (63)]. The criterion for significance was $\alpha<0.05$. We also relied on entropy, which is indicative of the degree of homogeneity within and independence between classes (60). Elevated scores of entropy indicate high independence and little spillover between classes. Furthermore, we examined the substantive interest of each model by evaluating how solutions compare with theoretical and empirical knowledge. Finally, although we selected a solution based primarily on unconditional models, we also investigated all solutions with predictors to determine whether all classes could be meaningfully differentiated (59). All models were estimated using maximum likelihood, and multiple initial values (5000 starts; 100 optimizations) were used to avoid local maxima. We imputed five datasets with an EM technique in SPSS (version 20.0) and replaced missing values by the mean of all imputed values. Mplus (version 7.0) software (64) was used for the LCA $(65,66)$.

After selecting a solution with an optimal number of classes, the obtained classes were compared on sociodemographic and psychosocial predictors in grade $7-8$ as well as on substancerelated problems the following year (grade 11). We evaluated the association between classes and each predictor with all predictors simultaneously in the model. Predictors were linked to class group membership using multinomial regression. For the outcome (attributed substance-related problems), we compared the means of the class model using equality of means test across classes based on posterior probability-based multiple imputation [AUXILIARY option in Mplus; (64)].

\section{RESULTS}

\section{DESCRIPTIVE STATISTICS}

Means and standard deviation for continuous variables as well as percentages for categorical variables are presented in Table 1. Missing data ranged from 1 (age) to 776 (48\%) (outcome) with a mean of $205(12.7 \%)$.

\section{SELECTION OF LATENT CLASS MODEL}

Comparisons of entropy and spillover indices, fit indices (deviance, AIC, BIC, SSBIC), and likelihood ratio tests for the one to six class LCA models suggested that the four-class model provided the best fit (see Table 2). As can be seen, model fit on all indices tended to improve as the number of classes increased, but the rate of improvement started to diminish around a four-class model. This solution had close to the lowest BIC and adjusted BIC scores with the highest entropy value of 0.83 (60). Likelihood ratio tests suggest few incremental validity beyond a four-class model.
Table 1 | Descriptive statistics for substance-use variables, predictors, and outcome.

\begin{tabular}{lll}
\hline$N$ & $\begin{array}{l}\text { Mean } \\
\text { (or \%) }\end{array}$ & SD \\
\hline
\end{tabular}

\section{PRÉDICTEURS (GRADE 7-8)}

Sex $(1=$ female)

Age

Family adversity

Delinquent behaviors

Depressive symptoms

Peer delinquency

Academic achievement

School Bonding

Parental monitoring

$\begin{array}{lll}1578 & 0.53 \quad 0.49\end{array}$

$\begin{array}{lll}1617 & 0.65 \quad 0.48\end{array}$

Conflict with parents

$1300 \quad 1.63 \quad 1.55$

$\begin{array}{lll}1377 & 2.60 & 3.45\end{array}$

$1345 \quad 8.68 \quad 7.48$

$1428 \quad 1.12 \quad 1.01$

$1448 \quad 77.30 \quad 39.62$

$1442 \quad 3.88 \quad 1.12$

$1390 \quad 1.90 \quad 0.70$

SUBSTANCE-USE (GRADE 10)

$\begin{array}{lll}1398 & 1.27 \quad 0.62\end{array}$

Alcohol early-onset (grade 8 or earlier)

$\begin{array}{lll}1169 & 0.76 \quad 0.43\end{array}$

Cannabis early-onset (grade 8 or earlier)

$1103 \quad 0.61 \quad 0.49$

Tobacco use (non-smoker)

1618

Occasional

13.8

Regular

28.2

Alcohol use frequency (0-5 times)

1448

6-30 Times

47.2

31 or more

Binge drinking frequency (never)

1 or 2 times

1610

3 or more

Number of drinks in typical occasion (0-3 drinks)

(4-6 Drinks)

(More than 6)

Cannabis use frequency (1-5 times)

6-30 Times

31 or more

Number of joints in typical occasion

Alcohol and cannabis simultaneous use

frequency (never)

1 or 2 times

3 or more

Stimulants/hallucinogens use frequency (never)

1 or 2 times

3 or more

42.0

25.0

1603

32.3

43.3

1362

26.3

10.0

$1370 \quad 0.46$

0.50

Outcome (grade 11)

1614

38.3

33.4

1601

20.8

23.8

$842 \quad 0.19$

SD, standard deviation.

Models with 5 and 6 classes did not significantly improve model fit over models with fewer classes. The removal of covariates and outcome did not result in a change to the four-class solution, contrary to other solutions, indicating that the assumption of local independence was not violated. The four-class model also appears better than simpler models and more clinically significant. The four classes are distinct and each represents a significant number of participants. And as we will see below, classes can be discriminated by their association with predictors and outcome. We thus selected a four-class model. 
Table 2 | Fit statistics, likelihood ratio tests, and entropy for different class solutions.

\begin{tabular}{|c|c|c|c|c|c|c|c|c|}
\hline & \multicolumn{4}{|c|}{ Fit indices } & \multicolumn{2}{|c|}{ Likelihood ratio tests } & \multirow[t]{2}{*}{ Entropy } & \multirow[t]{2}{*}{ Spill } \\
\hline & LL & BIC & SSBIC & AIC & VLMR & Adjusted LMR & & \\
\hline 1 Class & -45044 & 90361 & 90243 & 90161 & NA & NA & NA & NA \\
\hline 2 Classes & -13095 & 26522 & 26379 & 26279 & $2837.38(1)^{* * *}$ & $2823.731(1)^{* * *}$ & 83 & No \\
\hline 3 Classes & -12716 & 25971 & 25739 & 25578 & $757.79(2)^{* * *}$ & $754.14(2)^{* * *}$ & 83 & No \\
\hline 4 Classes & -12477 & 25700 & 25379 & 25156 & $478.17(3)^{* * *}$ & $475.87(3)^{* * *}$ & 83 & No \\
\hline 5 Classes & -12322 & 25598 & 25188 & 24903 & $308.73(4)$ & $307.24(4)$ & 81 & Yes \\
\hline 6 Classes & -12224 & 25607 & 25109 & 24761 & $197.02(5)$ & $196.07(5)$ & 80 & Yes \\
\hline
\end{tabular}

LL, loglikelihood; BIC, Bayesian information criterion; SSBIC, sample-size adjusted Bayesian information criterion; AIC, Aikaike information criterion; VLMR, Vuong-Lo-Mendell-Rubin likelihood ratio test for $k-1$ (HO) vs. k Classes; Adjusted LMR, Lo-Mendell-Rubin adjusted likelihood ratio test. ${ }^{* *} p<0.001$.

\section{CHARACTERISTICS OF THE FOUR LATENT CLASSES}

Four distinct classes based on use patterns were identified. These classes were labeled Late-Light Use (1; $N=454,28 \%)$, Late-Heavy + Polydrug Use $(2 ; N=222,14 \%)$, Early-Moderate Use (3; $N=526,33 \%)$, and Early-Heavy + Polydrug Use (4; $N=416,26 \%$ ) (see Figure 1). There are significant differences at the 0.05 level between all classes on all items except alcohol use precocity for comparisons with the Early-Heavy + Polydrug Use class, which had no variance on this item. There are differences between almost all items' categories. Late Onset/Light Users had the lowest levels of use on each substance-related indicator. Early-Heavy + Polydrug Users had the highest levels of use on most indicators. The other two classes fell in between. Tobacco use was the highest in the Early-Heavy + Polydrug Users, the lowest in Late-Light Users, and was similar between the two other classes. For alcohol use indicators (frequency, binge, typical quantity), Early-Heavy + Polydrug Users and Late-Heavy + Polydrug Users are at similar levels despite early-onsetters showing slightly heavier patterns. Once again, Late-Light Users showed the lowest levels with Early-Moderate Users falling in between. In terms of cannabis use indicators (frequency, typical quantity) as well as of stimulant/hallucinogens and of cannabis use and alcohol polyuse, we observe very similar patterns.

\section{SUBSTANCE-RELATED PROBLEMS OUTCOME}

As shown in Table 4, on a mean scale of the 14 substance-related harm items, scores were respectively $0.09,0.26,0.17$, and 0.36 for each class and were all mutually statistically different. As expected, the Early-Heavy + Polydrug Use class had the highest levels of problems $(M=0.36, \mathrm{SD}=0.012)$ and the Late-Light Use the lowest $(M=0.09 ; \mathrm{SD}=008)$. Notably, the Early-Moderate Use class had a lower level of problems $(M=0.17 ; \mathrm{SD}=009)$ than the Late-Heavy + Polydrug Use $(M=0.26 ; \mathrm{SD}=0.017)$.

\section{SOCIODEMOGRAPHIC, BEHAVIORAL, AND PSYCHOSOCIAL PREDICTORS OF SUBSTANCE-USE CLASSES}

As shown in Tables 3 and 4, significant differences were found between all classes. Odds ratios are calculated for a one standard deviation variation in predictors. Classes Late-Heavy + Polydrug Use and Early-Heavy + Polydrug Use were similar in terms of concurrent use in grade 10 . However, compared to the
Late-Heavy + Polydrug Use class, Early-Heavy + Polydrug Users had more problems in grade 11, and were older, had an earlier substance use onset (alcohol and cannabis), had a higher proportion of boys, more delinquent behaviors, deviant peers, and conflict with parents and were less monitored by them. Early-Moderate Use and Early-Heavy + Polydrug Use classes both are early-onsetters, but compared to the Early-Heavy + Polydrug Use class (and LateHeavy + Polydrug Use), the Early-Moderate Use class had more moderate patterns of use as reflected in less problems than in Late-Heavy + Polydrug Use or Early-Heavy + Polydrug Use classes. The Early-Moderate Use class had the highest proportion of female. It has lower peer deviancy proportions than EarlyHeavy + Polydrug Use class, but higher than Late-Light Use and Late-Heavy + Polydrug Use classes. It also has comparable levels of delinquent behaviors and parent monitoring with the EarlyHeavy + Polydrug Use class, which are at more problematic levels than in Late-Light Use and Late-Heavy + Polydrug Use classes. The Late-Light Use class had, in addition to the lowest level of problems, the lowest level of substance use as well as the lowest level of risk. This class is younger than all other three, it had higher levels of school bonding than both Late-Heavy + Polydrug Use and Early-Heavy + Polydrug Use classes, and it had the lowest peer deviancy but had similar levels of delinquent behaviors with the Late-Heavy + Polydrug Use class, which were lower than in Early-Moderate Use and Early-Heavy + Polydrug Use classes. A similar pattern emerged regarding parental monitoring. The Late-Light Use and Late-Heavy + Polydrug Use classes had similar levels, which were higher than in Early-Moderate Use and EarlyHeavy + Polydrug Use classes. The Late-Light Use class had also lower levels of conflicts than the Early-Heavy + Polydrug Use.

\section{DISCUSSION}

This study aimed to identify distinct latent classes of adolescent cannabis users based on their substance-use patterns in grade 10 and to distinguish these classes in terms of (1) sociodemographic and psychosocial predictors in grades 7-8 and (2) substancerelated problems in grade 11 . We identified four classes of cannabis use in adolescence: (1) Late-Light Use (2) Late-Heavy + Polydrug Use (3) Early-Moderate Use, and (4) Early-Heavy + Polydrug Use. Past typologies have generally found three or four cannabis users categories (5-8). However, some of these often relied on clinical 

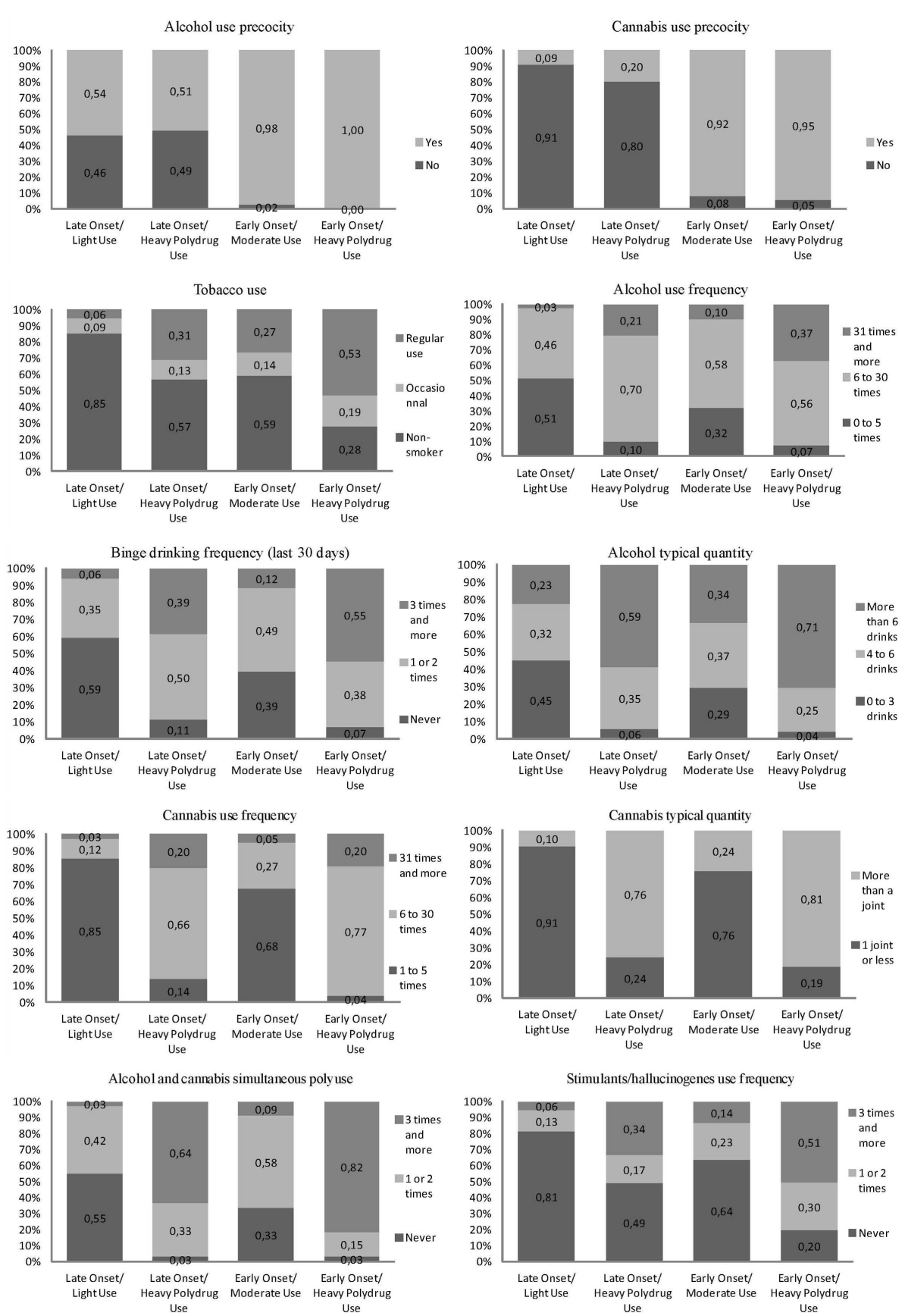

FIGURE 1 | Substance use items' category frequencies by classes.

samples (40) or adult population (5), whereas the current study examines a normative population of adolescents. As in other typologies, we found early and late onset classes. In general, EarlyHeavy + Polydrug Users had the scores associated with the greatest risk in early adolescence and reported the most problems in late adolescence. The category with least problems and risk was the Late-Light Use class. These two classes at the extremes of the continuum differed on almost every substance use indicators and predictors.
One major contribution of the present study was to distinguish between two types of early-onset classes. Interestingly, the EarlyModerate use class had an early alcohol and cannabis use onset as in the Early-Heavy + Polydrug use class but has less substancerelated problems. It even has fewer problems than the LateHeavy + Polydrug use class, which has a late onset but heavier use patterns. This suggests that proximal substance use behavior has an influence on the level of problems experienced obviously. Except for age and sex, the only variable to distinguish between early-onset 


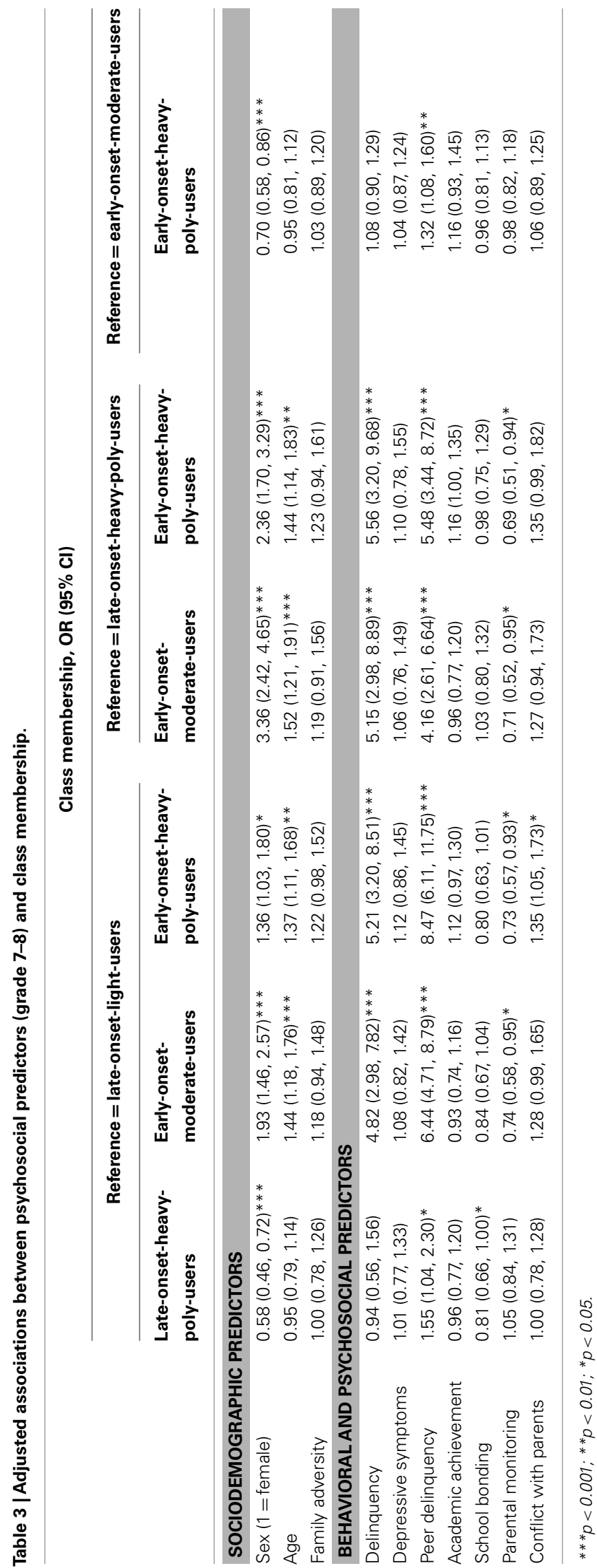

classes is peer delinquency, and between the late-onset classes is school bonding. Indeed, the Early-Heavy + Polydrug use class shows higher scores of peer delinquency than the Early-Moderate use class and the Late-Heavy Polydrug use has lower school bonding scores than the Late-Light use class. Moreover, despite possibly contributing to delaying onset (it is higher in both late onset classes), parental monitoring is no panacea because earlyonset classes are high and indistinguishable on that characteristic while showing an important difference in substance-related harm. Regarding the two intermediary classes (Late-Heavy + Polydrug use and Early-Moderate use), noteworthy are the lower delinquency and peer delinquency as well as higher parental monitoring scores in the Early-Moderate use class that has a generally lower level of use and consequences. Adolescents in the Early-Moderate use class may well be the popular ones [see Ref. (67)]. The inclusion of multidimensional predictors was useful to discriminate between classes. Indeed, age, sex, delinquent behaviors, peer deviancy, school bonding, and parental monitoring all contributed to discriminate classes. The inclusion of multiple substance use indicators seems to have also improved the discrimination between classes.

\section{IMPLICATIONS}

The results have many implications. First, they discriminate two different types of early as well as late onset cannabis users. They do so by shedding light on their distinctive relationships with risk factors from multiple dimensions as well as substance-related problems. Furthermore, our results, taken together, also shed light on the fact that not all early-onsetters are at elevated risk and experience a high level of substance-use related problems and that they are even at a lower level of risk than some late-onsetters. These results should be used to more meaningfully target and inform effective interventions toward users experiencing elevated levels of risks and harms. Moreover, a typology provides a useful heuristic for clinicians conducting assessment or screening with cannabisinvolved adolescents. Our results suggest that screening and intervention for risky cannabis use among adolescents should focus on school bonding in order to discriminate late-onset classes and on peer delinquency in order to discriminate early-onset classes. Intervention should be prioritized for the Early-Heavy + Polydrug use and Late-Heavy + Polydrug use classes. School bonding and peer deviancy seem to be good targets for intervention with either Early- or Late-Heavy + Polydrug Users and parental monitoring and conflict with parents seem to be further good targets for intervention with Early-Heavy + Polydrug users. In both cases (Early- or Late-Heavy + Polydrug), binge drinking, cannabis use frequency and alcohol and cannabis simultaneous use seem to be the most important substance-use behaviors to target in interventions. In the first case, working simultaneously on these use patterns, in addition to stimulants/hallucinogens use frequency, and psychosocial risk factors, with demand and harm reduction interventions, would probably be a good strategy whereas intervention with the latter group should focus primarily on use patterns. Indeed, it is noteworthy and important to take into account that the Late-Heavy + Polydrug use class is mostly constituted of females with lower levels of risk. These cannabis users are more difficult to predict, but they have important intervention needs. 
Estimated means

\begin{tabular}{lcccc} 
& $\begin{array}{l}\text { Late-onset- } \\
\text { light-users }\end{array}$ & $\begin{array}{l}\text { Late-onset-heavy- } \\
\text { poly-users }\end{array}$ & $\begin{array}{l}\text { Early-onset-moderate- } \\
\text { users }\end{array}$ & $\begin{array}{l}\text { Early-onset-heavy- } \\
\text { poly-users }\end{array}$ \\
\hline Attributed substance-related problems & 0.093 & 0.257 & 0.174 \\
\hline
\end{tabular}

The Early-Moderate Users would on their part benefit from early intervention strategies in order to prevent their use to shift from moderate to heavy as well as to prevent it to become more problematic. Overall, other than substance use behaviors, the main factors to target would generally be school bonding, delinquency, peer delinquency, and parental monitoring. In terms of policy implications, the current legal framework in Canada and elsewhere is characterized by the criminalization of all use; any cannabis use is defined as problematic (68). This approach differs from the one prevailing for alcohol, which has evolved to a public health framework $(69,70)$. Rather than focusing on use per se, priority is given to the risks and harms associated with problematic patterns of use (e.g., drunk driving). This way, targeted interventions may be applied to relevant behaviors (71). In our study, this could mean targeting binge drinking frequency and substance mixing behaviors as well as other substance use. Harm reduction strategies also seem to be potential useful tools in order to reduce cannabis-related problems.

\section{STRENGTHS AND LIMITATIONS}

This study has multiple strengths, including the simultaneous consideration of substance use severity indicators, predictors, and outcomes as well as their multidimensionality, and use of a large prospective community-based sample. However, this study is not without limitations. First, despite the fact that confidentiality was assured, response bias and common method variance could have influenced our results. Fortunately, the validity and reliability of self-reported data on substance use have been established (7274), but this has not been proved for self-report of problems. In addition, the sample comes from deprived areas, which is a limitation to the generalization of results. However, even if schools from deprived areas were sampled, individual scores of familial adversity vary and include participants from low familial adversity. Another limitation is related to the large amount of missing data and potential attrition bias. Also, the results do not provide information on the sequence of problem as well as the subgroup development over time. Finally, the inclusion of age of onset in the typology, while substance use indicators have been selected from grade 10 is another potential limitation to the current study.

\section{FUTURE STUDIES}

Future prospective studies should examine factors that explain transitions across these subtypes in time. This would however be complex because age of onset is included in the typology. Another important area of development is in the study of specific harm categories (relational, health, school, etc.) related to different patterns of use in order to better inform prevention and treatment efforts to target specific harms. Indeed, if different outcomes are related to different classes, intervention should not only target specific factors related to specific patterns but also focus on specific problems related to each. Which are the most important problems related to each class? Which classes are disproportionally represented for each problem? Another potential improvement over the current study is the use of more specific items for each other drugs than alcohol, Tobacco, and Cannabis (e.g., ecstasy, LSD, Speed, GHB, Ketamine, etc.) as well as substance use motives. Finally, a nationally representative sample would also improve the external validity of the typology.

\section{ACKNOWLEDGMENTS}

Thanks to funding from FRQSC (\#2007-NP-112947) and the Quebec Ministry of Éducation, Loisir et Sport.

\section{REFERENCES}

1. Johnston LD, O'Malley PM, Bachman JG, Schulenberg JE. Monitoring the Future national Survey Results on Drug Use, 1975-2012. Volume II: College Students and Adults Ages 19-50. Ann Arbor: University of Michigan (2013). 400 p.

2. Cazale L, Fournier C, Dubé G. Consommation d'alcool et de drogues »dans: Dubé, Gaëtane, et autres (Dir.). Enquête Québécoise sur le Tabac, l’alcool, la Drogue et le jeu Chez les élèves du Secondaire, 2008, Québec, Institut de la Statistique du Québec (2009). p. 91-147.

3. Lingford-Hughes A, Nutt D. Neurobiology of addiction and implications for treatment. Br J Psychiatry (2003) 182:97-100. doi:10.1192/bjp.182.2.97

4. Stice E, Myers MG, Brown SA. Relations of delinquency to adolescent substance use and problem use: a prospective study. Psychol Addict Behav (1998) 12:136-46. doi:10.1037/0893-164X.12.2.136

5. Fischer B, Rehm J, Irving H, Ialomiteanu A, Fallu J-S, Patra J. Typologies of cannabis users and associated characteristics relevant for public health: a latent class analysis of data from a nationally representative Canadian adult survey. Int J Methods Psychiatr Res (2010) 19(2):110-24. doi:10.1002/mpr.307

6. Wittchen H-U, Behrendt S, Höfler M, Perkonigg A, Rehm J, Lieb R, et al. A typology of cannabis related problems among individuals with repeated illegal drug use in the first three decades of life: evidence for heterogeneity and different treatment needs. Drug Alcohol Depend (2009) 102:151-7. doi:10.1016/j.drugalcdep.2009.02.012

7. Chabrol H, Chauchard E, Goutaudier N, van Leeuwen N. Exploratory study of the psychopathological profiles of adolescent cannabis users. Addict Behav (2012) 37:1109-13. doi:10.1016/j.addbeh.2012.05.005

8. Reboussin BA, Hubbard S, Ialongo NS. Marijuana use patterns among AfricanAmerican middle-school students: a longitudinal latent class regression analysis. Drug Alcohol Depend (2007) 90:12-24. doi:10.1016/j.drugalcdep.2007.02.006

9. Arseneault L, Cannon M, Witton J, Murray RM. Causal association between cannabis and psychosis: examination of the evidence. Br J Psychiatry (2004) 184:110-7. doi:10.1192/bjp.184.2.110

10. Hall W, Solowij N. Adverse effects of cannabis. Lancet (1998) 352:1611-6. doi:10.1016/S0140-6736(98)05021-1

11. Hall W, Pacula RL. Cannabis Use and Dependence: Public Health and Public Policy. Melbourne: Cambridge University Press (2003).

12. Iversen L. The Science of Marijuana. Oxford: Oxford University Press (2000).

13. Iversen L. Long-term effects of exposure to cannabis. Curr Opin Pharmacol (2005) 5:69-72. doi:10.1016/j.coph.2004.08.010 
14. Kalant H. Adverse effects of cannabis on health: an update of the literature since 1996. Prog Neuropsychopharmacol Biol Psychiatry (2004) 28:849-63. doi:10.1016/j.pnpbp.2004.05.027

15. Perkonigg A, Lieb R, Hofler M, Schuster P, Sonntag H, Wittchen H-U. Patterns of cannabis use, abuse and dependence over time: incidence, progression and stability in a sample of 1228 adolescents. Addiction (1999) 94:1663-78. doi:10.1046/j.1360-0443.1999.941116635.x

16. Ramaekers J, Berghaus G, van Laar M, Drummer OH. Dose related risk of motor vehicle crashes after cannabis use. Drug Alcohol Depend (2004) 73:109-19. doi:10.1016/j.drugalcdep.2003.10.008

17. Chen K, Kandel D, Davies M. Relationships between frequency and quantity of marijuana use and last year proxy dependence among adolescents and adults in the United States. Drug Alcohol Depend (1997) 46:53-67. doi:10.1016/S03768716(97)00047-1

18. Henquet C, Krabbendam L, Spauwen J, Kaplan CD, Lieb R, Wittchen H$\mathrm{U}$, et al. Prospective Cohort study of cannabis use, predisposition for psychosis, and psychotic symptoms in young people. Br Med J (2005) 330:11-4. doi:10.1136/bmj.38267.664086.63

19. Patton GC, Coffey C, Carlin JB, Degenhardt L, Lynskey M, Hall W. Cannabis use and mental health in young people: Cohort study. Br Med J (2002) 325:1195-8. doi:10.1136/bmj.325.7374.1195

20. Perkonigg A, Goodwin RD, Fiedler A, Behrendt S, Beesdo K, Lieb R, et al. The natural course of cannabis use, abuse and dependence during the first decades of life. Addiction (2008) 103:439-49. doi:10.1111/j.1360-0443.2007. 02064.x

21. Collins RL, Ellickson PL, Bell RM. Simultaneous polydrug use among teens: prevalence and predictors. J Subst Abuse (1998) 10:233-53. doi:10.1016/S08993289(99)00007-3

22. Brière FN, Fallu J-S, Descheneaux A, Janosz M. Predictors and consequences of simultaneous alcohol-cannabis use in high school students. Addict Behav (2011) 36(7):785-8. doi:10.1016/j.addbeh.2011.02.012

23. Andersson B, Hibell B, Beck F, Choquet M, Kokkevi A, Fotiou A, et al. Alcohol and Drug Use Among European 17-18 Year Old Students. Data from the ESPAD Project. Stockholm: The Swedish Council for Information on Alcohol and Other Drugs (CAN) and the Pompidou Group at the Council of Europe (2007).

24. Pape H, Rossow I, Storvoll EE. Under double influence: assessment of simultaneous alcohol and cannabis use in general youth populations. Drug Alcohol Depend (2009) 101(1-2):69-73. doi:10.1016/j.drugalcdep.2008.11.002

25. Schenshul JJ, Convey M, Burkholder G. Challenges in measuring concurrency, agency and intentionality in polydrug research. Addict Behav (2005) 30:571-4. doi:10.1016/j.addbeh.2004.05.022

26. Babor TF, Dolinsky Z, Meyer RE, Hesselbrock M, Hoffmann M, Tennen H. Types of alcoholics: concurrent and predictive validity of some classification schemes. Br J Addict (1992) 87:1415-31. doi:10.1111/j.1360-0443.1992.tb01921.x

27. Tarter R, Kirisci L, Mezzich A. Multivariate typology of adolescents with alcohol use disorder. Am J Addict (1997) 6:150-8. doi:10.1111/j.1521-0391.1997. tb00564.x

28. Mezzich A, Tarter R, Kirisci L, Clark D, Bukstein O, Martin C. Subtypes of early age onsetalcoholism. Alcohol Clin Exp Res (1993) 17:767-70. doi:10.1111/ j.1530-0277.1993.tb00838.x

29. Rowe CL, Liddle HA, Dakof GA. Classifying adolescent substance abusers by level of internalizing and externalizing symptoms. J Child Adolesc Subst Abuse (2001) 11:41-65. doi:10.1300/J029v11n02_03

30. Taylor J, Malone S, Iacono WG, McGue M. Development of substance dependence in two delinquency subgroups and nondelinquents from a male twin sample. J Am Acad Child Adolesc Psychiatry (2002) 41:386-93. doi:10.1097/ 00004583-200204000-00010

31. Hawkins JD, Catalano RF, Miller JY. Risk and protective factors for alcohol and other drug problems in adolescence and early adulthood: implications for substance abuse prevention. Psychol Bull (1992) 112:64-105. doi:10.1037/00332909.112.1.64

32. Loeber R. Natural histories of conduct problems, delinquency, and associated substance use: evidence for developmental progressions. In: Lahey BB, Kazdin AE, editors. Advances in Clinical Child Psychopathology. (Vol. 10), New York: Plenum (1989). p. 73-124.

33. Guo J, Hill KG, Hawkins JD, Catalano RF, Abbott RD. A developmental analysis of sociodemographic, family and peer effects on adolescent illicit drug initiation. J Am Acad Child Adolesc Psychiatry (2002) 41(7):838-45. doi:10.1097/00004583-200207000-00017

34. Petraitis J, Flay BR, Miller TQ. Reviewing theories of adolescent substance use: organizing pieces in the puzzle. Psychol Bull (1995) 117:67-86. doi:10.1037/ 0033-2909.117.1.67

35. Swadi H. Individual risk factors for adolescent substance use. Drug Alcohol Depend (1999) 55:209-24. doi:10.1016/S0376-8716(99)00017-4

36. Felgus MA, Caldwell SB, Hesselbrock V. Assessing alcohol involved adolescents: toward a diagnostic taxonomy. J Subst Use (2009) 14(1):49-60. doi:10.1080/ 14659890802211796

37. Steinhausen H-C, Winkler Metzke C. The validity of adolescent types of alcohol use. J Child Psychol Psychiatry (2003) 44(5):677-86. doi:10.1111/1469-7610. 00154

38. Windle M. An alcohol involvement typology for adolescents: convergent validity and longitudinal stability. J Stud Alcohol (1996) 57:627-37.

39. Thomas G, Flight J, Richard K, Racine S. Pour une Typologie de la Consommation de Cannabis Adaptée Aux Politiques Canadiennes: Analyse tirée de l'Enquête sur les Toxicomanies au Canada de 2004. Canada: CCLAT (2006).

40. Rowe C, Liddle H, Caruso J, Dakof G. Clinical variations of adolescent substance abuse: an empirically based typology. J Child Adolesc Subst Abuse (2004) 14(2):19-40. doi:10.1300/J029v14n02_02

41. Skrondal A, Rabe-Hesketh S, editors. Generalized Latent Variable Modeling. Washington, DC: Chapman \& Hall/CRC (2004).

42. Agrawal A, Lynskey M, Madden P, Bucholz KK, Heath AC. A latent class analysis of illicit drug abuse/dependence: results from the National Epidemiological Survey on alcohol and related conditions. Addiction (2006) 102:94-104. doi:10.1111/j.1360-0443.2006.01630.x

43. Grant J, Scherrer JF, Neuman R, Todorov AA, Pricem RK, Bucholz KK. A comparison of the latent class structure of cannabis problems among adult men and women who have used cannabis repeatedly. Addiction (2006) 101:1133-42. doi:10.1111/j.1360-0443.2006.01463.x

44. Lynskey M, Agrawal A, Bucholz KK, Nelson EC, Madden P, Todorov AA, et al. Subtypes of illicit drug users: a latent class analysis of data from an Australian twin sample. Twin Res Hum Genet (2006) 9:523-30. doi:10.1375/twin.9.4.523

45. Monga N, Rehm J, Fischer B, Brissette S, Bruneau J, el-Guebaly N, et al. Using latent class analysis (LCA) to analyze patterns of drug use in a population of illegal opioid users. Drug Alcohol Depend (2007) 8:1-7. doi:10.1016/j.drugalcdep. 2006.08.029

46. Patra J, Fischer B, Maksimowska S, Rehm J. Profiling poly-substance use typologies in a multi-site cohort of illicit opioid and other drug users in Canada - a latent class analysis (LCA). Addict Res Theory (2009) 17:168-85. doi:10.1080/16066350802372827

47. Janosz M, Bélanger J, Dagenais C, Bowen F, Abrami PC, Cartier SC, et al. Aller plus loin, Ensemble: Synthèse du Rapport Final d'évaluation de la Stratégie d'intervention Agir Autrement. Montreal: Groupe de recherche sur les environnements scolaires (2010).

48. Hibell B, Andersson B, Ahlström S, Balakireva O, Bjarnason T, Kokkevi A, et al. The 1999 ESPAD Report. Alcohol and Other Drug Use Among Students in 30 European Countries. Stockholm: The Swedish Council for Information on Alcohol and Other Drugs (CAN) and The Pompidou Group at the Council of Europe (2000).

49. Hibell B, Andersson B, Bjarnason T, Ahlström S, Balakireva O, Kokkevi A, et al. The ESPAD Report 2003. Alcohol and Other Drug Use Among Students in 35 European Countries. Stockholm: The Swedish Council for Information on Alcohol and Other Drugs (CAN) and the Pompidou Group at the Council of Europe (2004).

50. Le Blanc M. MASPAQ: Mesures de l'adaptation Personnelle et Sociale pour les Adolescents québécois: Manuel et Guide d'utilisation [Measures of Quebec Adolescent' Social and Personal Adjustment: User's Guide (3rd ed.)]. Montreal: University of Montreal (1996).

51. Germain M, Guyon L, Landry M, Tremblay J, Brunelle N, Bergeron J. La grille de dépistage de Consommation Problématique d'alcool et de Drogues chez les Adolescents et les Adolescentes (DEP-ADO). Version 3.1. Montréal, QC: RISQ (2005). 2005 p.

52. Landry M, Tremblay J, Guyon L, Bergeron J, Brunelle N. La Grille de dépistage de la consommation problématique d'alcool et de drogues chez les adolescents et les adolescentes (DEP-ADO): développement et qualités psychométriques. Drogues, santé et société (2004) 3(1):35-67. doi:10.7202/010517ar 
53. Jöreskog KG, Sörbom D. Advances in Factor Analysis and Structural Equation Models. New York: University Press of America (1979).

54. Deas D, Thomas S. Comorbid Psychiatric Factors Contributing to Adolescent Alcohol and Other Drug Use. Bethesda: National Institute on Alcohol Abuse and Alcoholism (2002).

55. Petraitis J, Flay BR, Miller TQ, Torpy EJ, Greiner B. Illicit substance use among adolescents: a matrix of prospective predictors. Subst Use Misuse (1998) 33:2561-604. doi:10.3109/10826089809059341

56. Radloff LS. The CES-D Scale: a self-report depression scale for research in the general population. Appl Psychol Meas (1977) 1(3):385-401. doi:10.1177/ 014662167700100306

57. Radloff LS. The use of the center for epidemiologic studies depression scale in adolescents and young adults. J Youth Adolesc (1991) 20(2):149-66. doi:10.1007/ bf01537606

58. Riddle AS, Blais MR, Hess U. A Multi-Group Investigation of the CES-D's Measurement Structure Across Adolescents, Young Adults and Middle-Aged Adults. Montreal: Centre interuniversitaire de recherche en analyse des organisations (CIRANO) (2002).

59. Muthén B. Latent variable analysis: growth mixture modeling and related techniques for longitudinal data. In: Kaplan D, editor. Handbook of Quantitative Methodology for the Social Sciences. Newbury Park, CA: Sage Publications (2004). p. $345-68$.

60. Raftery AE. Bayesian model selection in social research. In: Marsden PV, editor. Social Methodology. Oxford: Blackwell (1995). p. 111-96.

61. Li W, Nyholt DR. Marker selection by Akaike information criterion and Bayesian information criterion. Genet Epidemiol (2001) 21(Supp 1):S272-7.

62. Lo Y, Mendell N, Rubin D. Testing the number of components in a mixture model. Biometrika (2001) 88:767-78. doi:10.1093/biomet/88.3.767

63. Nylund KL, Asparouhov T, Muthén BO. Deciding on the number of classes in latent class analysis and growth mixture modeling: a Monte Carlo simulation study. Struct Equation Model (2007) 14(4):535-69. doi:10.1080/ 10705510701575396

64. Muthén LK, Muthén BO. Mplus User's Guide. Seventh Edition. Los Angeles, CA: Muthén \& Muthén (2012).

65. Enders CK. Applied Missing Data Analysis. New York, NY: Guilford Press (2010).

66. Graham JW. Missing data analysis: making it work in the real world. Annu Rev Psychol (2009) 60:549-76. doi:10.1146/annurev.psych.58.110405.085530

67. Fallu J-S, Brière FN, Vitaro F, Cantin S, Borge AIH. The influence of close friends on adolescent substance use: does popularity matter? In: Ittel A, Merkens H, Stecher L, editors. Jahrbuch Jugendforschung. (Vol. 10), Wiesbaden: VS Verlag (2011). p. 235-62.
68. Fischer B, Ala-Leppilampi K, Single E, Robins A. Cannabis law reform in Canada: is the 'saga of promise, hesitation and retreat' coming to an end? Can J Criminol Crim Justice (2003) 45:265-97. doi:10.3138/cjccj.45.3.265

69. Hall W. What's in a name? Addiction (2007) 102:692-692. doi:10.1111/j.13600443.2007.01812.x

70. Room R, Babor T, Rehm J. Alcohol and public health: a review. Lancet (2005) 365:519-30. doi:10.1016/S0140-6736(05)17870-2

71. Babor T, Caetano R, Casswell S, Edwards G, Giesbrecht N, Graham K, et al. Alcohol: No Ordinary Commodity: Research and Public Policy. Oxford: Oxford University Press (2003).

72. Fals-Stewart W, O'Farrell T, Freitas T, McFarlin S, Rutigliano P. The timeline followback reports of psychoactive substance use by drug-abusing patients: psychometric properties. J Consult Clin Psychol (2000) 68:124-44. doi:10.1037/ 0022-006X.68.1.134

73. Johnston LD, O'Malley PM. Issues of validity and population coverage in student surveys of drug use. In: Rowe BA, Kozel NJ, Richards LG, editors. Self-Report Methods of Estimating Drug Use: Meeting Current Challenges to Validity (NIDA Research Monograph No. 57). Rockville, MD: National Institute on Drug Abuse (1985). p. 31-54.

74. Oetting ER, Beauvais R. Adolescent drug use: findings of national and local surveys. J Consult Clin Psychol (1990) 58:385-94. doi:10.1037/0022-006X.58.4.385

Conflict of Interest Statement: The authors declare that the research was conducted in the absence of any commercial or financial relationships that could be construed as a potential conflict of interest.

Received: 04 October 2013; accepted: 17 January 2014; published online: 07 February 2014.

Citation: Fallu J-S, Brière FN and Janosz M (2014) Latent classes of substance use in adolescent cannabis users: predictors and subsequent substance-related harm. Front Psychiatry 5:9. doi: 10.3389/fpsyt.2014.00009

This article was submitted to Addictive Disorders and Behavioral Dyscontrol, a section of the journal Frontiers in Psychiatry.

Copyright (C) 2014 Fallu, Brière and Janosz. This is an open-access article distributed under the terms of the Creative Commons Attribution License (CC BY). The use, distribution or reproduction in other forums is permitted, provided the original author(s) or licensor are credited and that the original publication in this journal is cited, in accordance with accepted academic practice. No use, distribution or reproduction is permitted which does not comply with these terms. 